\title{
Effect of platelet-rich plasma on the implant bone defects in rabbits through FAK/PI3K/AKT signaling pathway.
}

\author{
Wei Liu', Ben Chen', Youyang Zheng ${ }^{1}$, Yuehua Shi², Zhuojin Shi²* \\ ${ }^{1}$ Department of Stomatology, $2^{\text {nd }}$ Affiliated Hospital, School of Medicine, Zhejiang University, Hangzhou, PR China \\ ${ }^{2}$ School of Stomatology, Zhejiang Chinese Medical University, Hangzhou, PR China
}

\begin{abstract}
Objective: Platelet-Rich Plasma (PRP) has been shown to be a beneficial growth factor for bone tissue healing and used in implantology. The aim of this study was to investigate the effects of PRP in bone defects in rabbits.

Methods: Twenty rabbits were used to establish the implant bone defects model in this study. An intrabony defect $(5 \mathrm{~mm} \times 5 \mathrm{~mm} \times 3 \mathrm{~mm})$ was created in alveolar bone of lower jar of each rabbit. The wound was treated with PRP. The expression of Platelet-Derived Growth Factor BB (PDGFBB) was assessed by Enzyme-Linked Immunosorbent Assay (ELISA). The Focal Adhesion Kinase (FAK) and related Phosphatidylinositol 3-Kinase (PI3K)/AKT (protein kinase B) were measured by Western blot.

Results: The results showed that PRP could significantly improve the bone healing process when compared with control, meanwhile $10 \%$ PRP could markedly increase fibroblast $48 \mathrm{~h}$ post treatment. PDGFBB was higher in PRP group than that in control group. PRP treatment also could elevate the phosphorylation of FAK and PI3K/AKT, however the inhibitor of PDGFR could reverse this trend.

Conclusion: The results suggested PRP treatment improves the bone healing process through the FAK/ PI3K/AKT pathway.
\end{abstract}

Keywords: PRP, FAK, PI3K/AKT.

Accepted on December 5, 2017

\section{Introduction}

Alveolar bone defects occurs as a result of facial trauma and jawbone cysts [1], and bone augmentation procedures are difficult and necessary [2,3]. As we know, an autogenously bone transplant is too hard to perform in clinical surgery. The healing of wound is mediated by a lot of intra-and extracellular factors that are regulated by signaling pathway proteins [4]. Platelet-Rich Plasma (PRP) has been used in clinical for implantology and demonstrated to increase the rate of bone regeneration and bone deposition [2,4]. The PRP is a intracellular storage pool of growth factors and cytokines, such as Platelet-Derived Growth Factor (PDGF), Transforming Growth Factor $\beta 1$ and $\beta 2$ (TGF $\beta 1$ and $\beta 2$ ), Insulin-Like Growth Factor-1 (IGF-1), Vascular Endothelial Growth Factor (VEGF), basic fibroblast growth factor and platelet-activating factor [4-6]. Once the active proteins are secreted, some of these proteins could bind to transmembrane receptors of the wound. After that, many intracellular signal proteins are activated. PRP has important functions in several physiological processes including cellular proliferation, collagen synthesis, angiogenesis, and so on [7,8].

PDGF is a family of 5 homo- and heterodimers encoded by 4 genes (A-D). Among these factors, PDGF BB, which has the strong effects in osteoblasts and promotes angiogenesis and collagen synthesis, could improve the wound healing process $[4,9,10]$.

However, PRP has been used in clinical surgery, the mechanism needs to be elucidated. FAK, a $125 \mathrm{kD}$ tyrosine kinase, is one of the most important kinase which could be activated once its structure is changed by integrins. Activated FAK could trigger the cascade of PI3K/AKT pathway. Previous studies demonstrate that $\mathrm{PI} 3 \mathrm{~K} / \mathrm{AKT}$ pathway is involved in cell survival and growth $[11,12]$.

In this study, the artificial bone defects of the rabbit mandible was used to evaluate the effects of PRP on the bone regeneration, and the focal adhesion kinase (FAK) and $\mathrm{PI} 3 \mathrm{~K} / \mathrm{AKT}$ pathway proteins were also assessed.

\section{Methods}

\section{Animals}

Twenty New Zealand albino rabbits, weighting 2-2.5 kg, were housed under a constant $12 \mathrm{~h}$ light-dark cycle, humidity (50-60\%) with free access to food and water. Before experiments, the animals were allowed to habituate to the housing facilities for a week. The present study was conducted 
with approval from the Animal Ethics Committee of the University.

The rabbit was put in a fixator and general anesthesia was induced by intraperitoneal (i.p.) injection with pentobarbital $(30 \mathrm{mg} / \mathrm{kg}$ ). Then, the incision site was shaved and sterilized. Local anesthesia to the lower gingival was induced by injection of $0.5 \%$ lidocaine $\mathrm{HCl} \quad 0.2 \mathrm{ml}$ containing 1:100,000 epinephrine. The both second premolar of low jar were extracted. The right side wound was treated with PRP and the left side wound was used as control.

Three months after tooth extraction, rabbits were under anesthesia. The mandibular bone was scraped into a round shape under continuous rinsing sterile water with a dental drill, and the length was $8 \mathrm{~mm}$. Then the intrabony defect $(5 \mathrm{~mm} \times 5$ $\mathrm{mm} \times 3 \mathrm{~mm}$ ) was created in alveolar bone of lower jar of each rabbit. After that, the dental implants were placed through the defect, which was intact with the bone tissue.

\section{Preparation of PRP}

The procedure was based on the method descried by Masago et al. [2]. Briefly, $10 \mathrm{ml}$ autologous blood from femoral vein of each rabbit added by EDTA-2K was centrifuged at $20^{\circ} \mathrm{C}$ for 15 min at $800 \mathrm{rpm}$, and the plasma portions were again centrifuged for $15 \mathrm{~min}$ at $1300 \mathrm{rpm}$. The lower stratum platelet counts were performed. The number of platelet of PRP was concentrated 4- to 5.5-fold in comparison to the whole blood. The PRP was activated with $10 \%$ calcium chloride saline solution and the same volume of $100 \mathrm{U} / \mathrm{ml}$ bovine thrombin before application, and then the PRP turned into a gel-like substance.

\section{Application of PRP}

All the implants were stable during the experiment, the bone defects were treated with or without PRP gel, and all the defects area was covered with absorbable collagen membrane, and then the gum was sutured with 4.0 silk thread. All the rabbits were administrated with $50,000 \mathrm{IU} / \mathrm{kg}$ penicillin $\mathrm{G}$ once daily for $3 \mathrm{~d}$ post-surgery.

In vitro cell experiment, 5\%, 10\% PRP were added in the treated groups, while the control group was treated with same volume normal plasma.

\section{Histological assessment}

At the end of the experiment, the rabbits were euthanized by an intravenous (i.v) injection of pentobarbital solution. The mandibles containing the implant and defects area were removed and immediately fixed in $10 \%$ neutral buffered formalin. Dehydration of the specimens was performed in a graded series of ethanol (70-100\%), and embedded in lightcuring resin. The bone was cut mid-axially to a thickness of 30 $\mu \mathrm{m}$, and then sections were stained with methylene bluefuchsin acid. All sections were observed and captured with the microscope. The percentage of newly formed bone was evaluated by measuring the area of newly bone formation area in comparison with the total area of bone defects.

\section{Cell proliferation assay}

The cell viability was tested using MTT method. The cells were seeded in a 96-well plate, and incubated for 24 h, 48 h, 72 $\mathrm{h}, 96 \mathrm{~h}$ and $120 \mathrm{~h}$. MTT was added into each well and incubated for another $4 \mathrm{~h}$, then, $150 \mu \mathrm{l}$ acidic isopropanol was added. The plate reader Envision was used to measure the absorbance at $595 \mathrm{~nm}$.

\section{Enzyme-linked immunosorbent assay (ELISA)}

The growth factor of PDGFBB in tissue around the defects of alveolar bone $4 \mathrm{w}$ post-surgery was measured by ELISA according to ELISA kit instructions. The plates were determined at $450 \mathrm{~nm}$ with microplate reader.

\section{Western blot assay}

Tissue of alveolar or in vitro cultured cells was homogenized in RIPA buffer containing protease and phosphatase inhibitor cocktail according to the kit instruction. The protein samples concentration was detected by BCA protein quantification kit. Samples of each group were added up to $30 \mu \mathrm{g}$ and subjected to SDS-PAGE electrophoresis separation, and then transferred to the PVDF membrane. The samples were closed with $5 \%$ fatfree milk for $1 \mathrm{~h}$ and added to $50 \mathrm{~g} / \mathrm{L}$ BSA diluted antibody FAK, p-FAK, Akt, p-Akt, PI3K, p-PI3K, PDGFR $\beta$, pPDGFR $\beta$. The membrane was washed by TBST $(1 \mathrm{ml} / \mathrm{L}$ Tween-20) three times (5 min/times) after incubating at $4^{\circ} \mathrm{C}$ overnight, and then added to HRP (Santa Cruz, USA) labeled secondary antibody (1: 10000). The membrane was incubated at room temperature for $2 \mathrm{~h}$ and was washed by TBST 3 times (10 min/times). ECL chemiluminescent darkroom development was used. The protein expression level was normalized by $\beta$ actin, and the gray scale was scanned and quantified by software Image-J.

\section{Statistical analysis}

Data are expressed as mean \pm SD. Statistical differences were evaluated by software SPSS 19.0. Statistical analysis was performed using one-way analysis of variance, and $p$ values of less than 0.05 were considered as statistically significant.

\section{Results}

\section{PRP improved the wound healing after implanting}

Histimorphometric analysis was performed using methylene blue-fuchsin acid staining method. The results were presented in Figure 1. The new bone formation was significantly higher in PRP group than that in control group $(\mathrm{P}<0.05)$. Compared with the control group, the area of new bone was relative robust in PRP group. And it is hard to see the line of demarcation between the old and new bone in the wound area. 


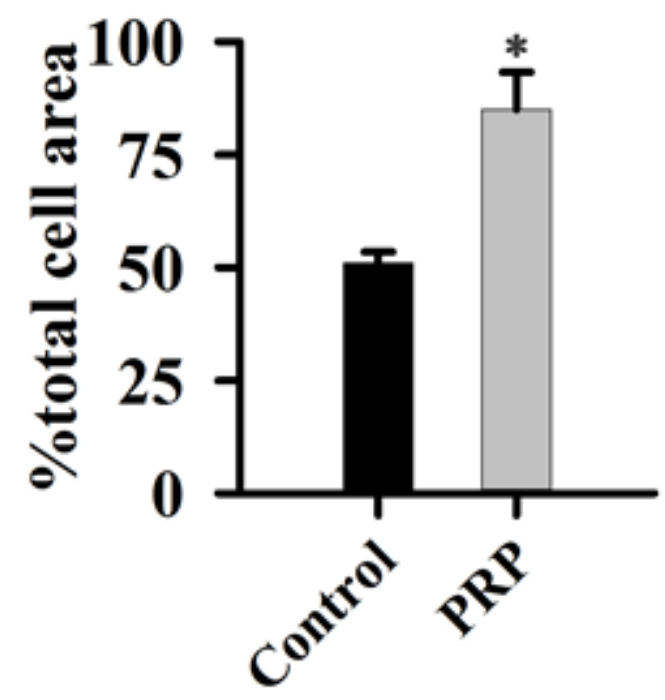

Figure 1. Effect of PRP on wound healing after implanting.

\section{Effect of PRP on the proliferation of fibroblast cells}

To determine whether PRP treatment promote fibroblast cells, we treated cells with different concentration of PRP for different time. PRP treatment could improve cells proliferation after $48 \mathrm{~h}$ (Figure 2). The proliferation effects were in a dose and time dependent manner.

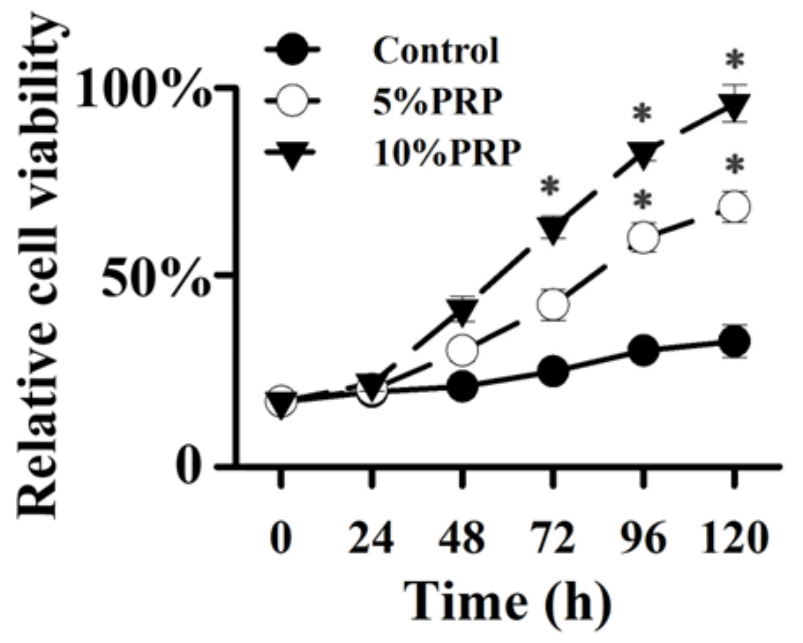

Figure 2. Effect of PRP on proliferation of fibroblast cells.

\section{Effect of PRP on the levels of PDGFBB}

When rabbits were treated with PRP, the changes of PDGFBB of the tissue around the defects of alveolar bone were shown in Figure 3. As compared with the control group, the PDGFBB was markedly increased after rabbits were treated with PRP for $4 \mathrm{w}(\mathrm{P}<0.01)$. Eight weeks post-surgery, the levels of PDGFBB of treated group were still higher than that of control group $(\mathrm{P}<0.05)$, while the levels were reduced when compared to $\mathrm{w}$ 4. The PDGFBB are released from platelets at the injury sites, thus accelerating the process of wound healing.

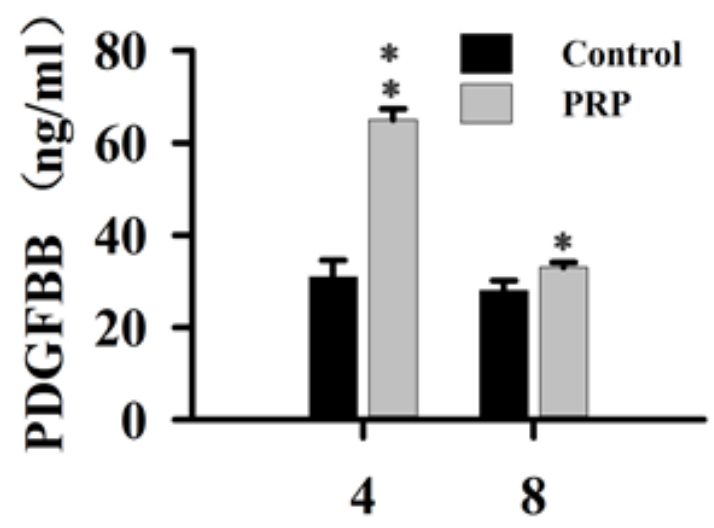

Figure 3. Effect of PRP on the levels of PDGFBB.

\section{Effect of PRP on the levels of FAK, PI3K, and AKT phosphorylation}

To determine the activation of FAK, PI3K and AKT in fibroblast cells, cells were treated with PRP and different inhibitors, the phosphorylation of these proteins were evaluated by Western Blot. As shown in Figure 4, the phosphorylation of FAK (Tyr 397), and AKT were significantly increased after PRP treatment for $20 \mathrm{~min}$ and $40 \mathrm{~min}$. When cells treated with inhibitor of PI3K, the phosphorylation levels of PI3K, AKT and FAK were markedly reduced in this study (Figure 4). The inhibitor of AKT could reduce the phosphorylation of AKT and FAK (Figure 5), meanwhile when cells incubated with FAK inhibitor, the phosphorylation of FAK was dramatically blocked. These results suggested that the phosphorylated PI3K/AKT could activate FAK with treatment with PRP.
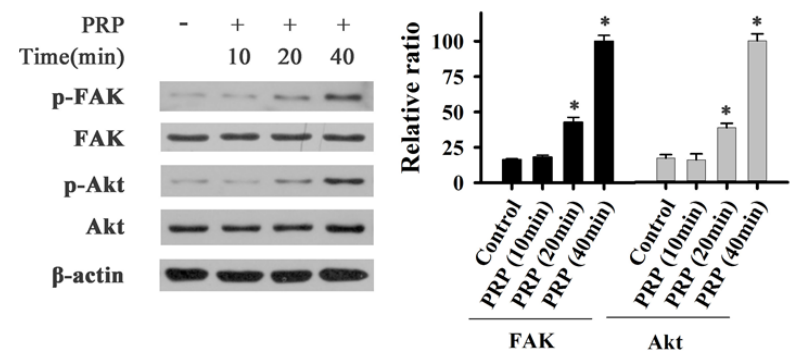

Figure 4. Effect of PRP on phosphorylation of FAK and AKT of fibroblast cells.

\section{Effect of PDGF on the levels of FAK, PI3K, and AKT phosphorylation}

When fibroblast cells treated with PRP medium, the PDGF receptor $\beta$ (PDFGR $\beta$ ) could be activated in this experiment (Figure 6). Treatment if the cells with the inhibitor of PDGFR, completely inhibited the PDFGR $\beta$ phosphorylation. While cells treated with inhibitor of PI3K, AKT, or FAK, did not affect the phosphorylation of PDFGR $\beta$. These results demonstrated that PRP activated the phosphorylation of FAK through PDGF pathway. 

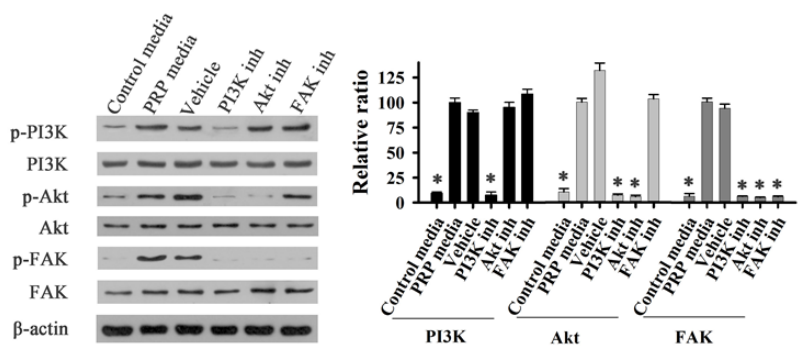

Figure 5. Effects of PIBK and FAK inhibitors on phosphorylation of PI3K, AKT and FAK of fibroblast cells. Control media: control group; PRP media: PRP group; Vehicle: positive group with PDGFBB; $P I 3 K$ inh: $P R P+P I 3 K$ inhibitor group; $A K T$ inh: $P R P$ $+A K T$ inhibitor group; FAK inh: AKT inh: PRP $+F A K$ inhibitor group.
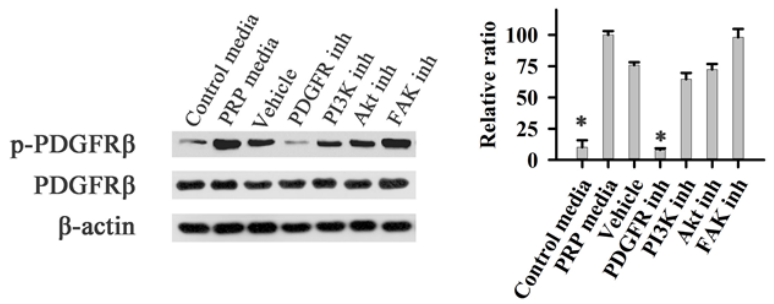

Figure 6. Effects of PRP on phosphorylation of PDGFR of fibroblast cells. Control media: control group; PRP media: PRP group; Vehicle: positive group with PDGFBB; PI3K inh: $P R P+P I 3 K$ inhibitor group; AKT inh: $P R P+A K T$ inhibitor group; FAK inh: AKT inh: PRP $+F A K$ inhibitor group.

\section{Discussion}

PRP has been reported to promote tissue repair and bone regeneration [13]. And the effects of PRP in implantology has been well studied in vitro and in vivo studies [14,15]. Platelets are derived from blood megakaryocytes of bone marrow and then are divided to inactive cells and active cells. PRP could release many growth factors, such as PDGF, IGF-1 and TGF$\beta 1$ [16-18]. Wiltfanng et al. has evaluated the effects of PRP on the regeneration of bony defects in the forehead area in minipigs [19]. Twelve weeks post-surgery, the results demonstrated a dramatical effect of bone regeneration in the autogenous group when animals treated with PRP. Accumulating evidence suggested that PRP treatment is a powerful strategy for bone defect repair.

In this experiment, new bone formation was significantly higher in PRP group than that in control group (Figure 1) and also PDGFBB of the tissue around the defects of alveolar bone (Figure 3) was markedly increased after rabbits were treated with PRP for $4 \mathrm{w}$. PDGFBB is a growth factor released form the $\alpha$-granules of PRP and it is important for wound healing process. These growth factors will transduct the signal into the interior of the cell through transmembrane proteins. Integrin region is considered the most important for bone regeneration. Integrins are herterodimeric transmembrance glycoproteins [20]. Within the cell, integrin will activate PI3K/AKT pathway. Our results was consist with these reports (Figures 4-6), when cell treated with PRP, PI3K/AKT proteins were significantly activated. Focal Adhesion Kinase (FAK), an adapter protein of the tyrosine kinase group, could be activated by PI3K/AKT pathway. FAK was activated with phosphorylation at tyrosine 397, and its structure was changed. Then FAK will create a high-affinity site for binding to protein PI3K $[18,21]$.

In this study, different inhibitors were used to identify the role of PAK in bone regeneration. The results war in agreement with the findings that PI3K/AKT pathway could activate FAK during the bone defect healing process with treatment with PRP.

\section{Conclusion}

In conclusion, our data demonstrated that PRP has the effects of promoting bone defects healing and proliferation of fibroblast cells. PI3K/AKT/FAK signaling pathway is partially involved in this process.

\section{Acknowledgement}

We thank the financial support from Natural Science Foundation of Zhejiang Province of China (LQ15H140004).

\section{References}

1. Peng W, Kim I, Cho H, Seo JH, Lee DH, Jang JM. The healing effect of platelet-rich plasma on xenograft in periimplant bone defects in rabbits. Maxillofac Plast Reconstr Surg 2016; 38: 16-24.

2. Masago H, Shibuya Y, Munemoto S, Takeuchi J, Umeda M, Komori T, Kuboki Y. Alveolar ridge augmentation using variuos bone substitutes-a web form of titanium fibers promotes rapid bone development. Kobe J Med Sci 2007; 53: 257-263.

3. Ortolani E, Guerriero M, Coli A, Giannuario A, Minniti G, Polimeni A. Effect of PDGF, IGF-1 and PRP on the implant osseointegration. An histological and immunohistochemical study in rabbits. Annali di Stomatologia 2014; 2: 66-68.

4. Gabling VLW, Acl Y, Springer IN, Hubert N, Wiltfang J. Platelet-rich plasma and platelet-rich fibrin in human cell culture. Oral Masillofac Impl 2009; 108: 48-55.

5. Torres J, Tamimi F, Alkhraisat MH. Platelet-rich plasma may prevent titanium-mesh exposure in alveolar ridge augmentation with an organic bovine bone. J Clin Periodontol 2010; 37: 943-951.

6. Dohan DM, Choukroun J, Diss A. Platelet-rich fibrin (PRF): a second-generation platelet concentrate. Part I: Technological concepts and evolution. Oral Surg Oral Med Oral Pathol Oral Radiol Endod 2006; 101: 37-44.

7. Chang PC, Seol YJ, Cirelli JA. PDGF-B gene therapy accelerates bone engineering and oral iplant osseointegration. Gene Ther 2010; 17: 95-104.

8. Hollinger JO, Hart CE, Hirsch SN, Lynch S, Friedlaender GE. Recombinant human platelet-derived growthfactor: Biology and clinical applications. J Bone Joint Surg Am 2008; 90: 48-54. 
9. Fredriksson L, Li H, Eriksson U. The PDGF family: four gene products form five dimeric isoforms. Cytokine Growth Factor Rev 2004; 15: 197-204.

10. Li X, Ponten A, Aase K, Karlsson L, Abramsson A, Uutela M. PDGF-C is a new protease-activated ligand for the PDGF alpha-receptor. Nat Cell Biol 2000; 2: 302-309.

11. Krtolica A, Parrinello S, Lockett S, Desprez PY, Campisi J. Senescent fibroblasts promote epithelial cell growth and tumorigenesis: a link between cancer and aging. Proc Natl Acad Sci USA 2001; 98: 12072-12077.

12. Yamamoto D, Sonoda Y, Hasegawa M, Funakoshi-Tago M, Aizu-Yokota E, Kasahara T. FAK overexpression upregulates cyclin D3 and enhances cell proliferation via the PKC and PI3-kinase-Akt pathways. Cell Signal 2003; 15: $575-583$.

13. Fennis JPM, Stoelinga PJW, Jansen JA. Mandibular reconstruction: a histological and histomorphometric study on the use of autogenous scaffolds, particulate corticocancellous bone grafts and platelet rich plasma in goats. Int J Oral Maxillofac Surg 2004; 33: 48-55.

14. Yun JH, Han SH, Choi SH. Effects of bone marrow derived mesenchymal stem cells and platelet-rich plasma on bone regeneration for osseointegration of dental implants: Preliminary study in canine three-wall intrabony defects. J Biomed Mater Res B Appl Biomater 2013.

15. Kaigler D, Avila G, Wisner-Lynch L. Platelet-derived growth factor applications in periodontal and peri-implant bone regeneration. Expert Opin Biol Ther 2011; 11: 375-385.

16. Cabbar F, Guler N, Kurkcu M. The effect of bovine bone graft with or without platelet-rich plasma on maxillary sinus floor augmentation. J Oral Maxillofac Surg 2011; 69: 2537-2547.

17. Kurikchy MQ, Al-Rawi NH, Ayoub RS. Histological evaluation of bone healing using organic bovine bone in combination with platelet-rich plasma (an experimental study on rabbits). Clin Oral Investig 2013; 17: 897-904.

18. Kong D, Chen F, Sima N. Inhibition of focal adhesion kinase induces apoptosis in bladder cancer cells via Src and the phosphatidylinositol 3-kinase/Akt pathway. Exp Ther Med 2015; 10: 1725-1731.

19. Wiltfang J, Kloss FR, Kessler P. Effects of platelet rich plasma on bone healing in combination with autogenous bone and bone substitutes in critical-size defects. An animal experiment. Clin Oral Implants Res 2004; 15: 187-193.

20. Thorwarth M, Wehrhan F, Schultze-Mosgau S. PRP modulates expression of bone matrix proteins in vivo without long-term effects on bone formation. Bone 2006; 38: 30-40.

21. Gusmao CV, Belangero WD. How do bone cells sense mechanical loading? Rev Bras Orthop 2009; 44: 299-305.

\section{*Correspondence to}

Zhuojin Shi

School of Stomatology

Zhejiang Chinese Medical University

PR China 